\title{
Effect of Supplementation with Iron Fortified Biscuits on the Hemoglobin Status of Children in Rural Areas of Shimoga, Karnataka: Correspondence
}

\author{
Neha Sareen $^{1} \cdot$ Aakriti Gupta $^{1} \cdot$ Radhika Kapil $^{1}$
}

Received: 28 April 2015 / Accepted: 18 April 2016/Published online: 11 May 2016

(C) Dr. K C Chaudhuri Foundation 2016

To the Editor: We read with great interest, the article entitled 'Effect of supplementation with iron fortified biscuits on the hemoglobin status of children in rural areas of Shimoga, Karnataka' [1]. There are few following methodological issues which need to be clarified by the authors of this publication so that the readers of the IJP are benefitted.

The authors have taken hemoglobin cut-offs of $11.5 \mathrm{~g} / \mathrm{dl}$ for all children in the age group of 6-12 $\mathrm{y}$. According to WHO, the hemoglobin cut-offs to be utilized for classification of anemia is $11.5 \mathrm{~g} / \mathrm{dl}$ for children in the age group of 5-11 y and $12.0 \mathrm{~g} / \mathrm{dl}$ for children $11-<14 \mathrm{y}$. The anemia classification utilized in the study is not valid [2].

The Recommended Dietary Allowances (RDA) of iron for children as per Indian Council of Medical Research, 2010, for the age group of 7-9 y is $16 \mathrm{mg} / \mathrm{d}$. Similarly, the RDA for children in the age group of 10-12 y for boys and girls is $21 \mathrm{mg} / \mathrm{d}$ and $27 \mathrm{mg} / \mathrm{d}$, respectively [3]. According to the study, children in Group 1 were given $30 \mathrm{mg}$ of iron $(30 \mathrm{mg} / 6$ biscuits). The supplemental dose was more than $200 \%$ of the RDA for children in 7-9 y. Hence, in this study, a high dose of supplementation of iron was administered. The food fortification strategies recommend only $30 \%$ of the RDA for a nutrient to be added under the fortification program with micronutrients.

Neha Sareen

nehasareen088@gmail.com

1 Department of Human Nutrition, All India Institute of Medical Sciences, Ansari Nagar, New Delhi 110029, India
It is not clear from the research methodology, whether it was supervised administration consumption of biscuits by students, especially on holidays.

The mean weight gain in the Group I with high doses of iron fortified biscuits was $1.7 \mathrm{~kg}$ in $120 \mathrm{~d}$. It is an interesting finding as this was achieved without significant increase in nutrients like calories, protein and fats.

The increase in hemoglobin amongst children with 7, 8, 9, 10 and $11 \mathrm{~g}$ of $\mathrm{Hb} / \mathrm{dl}$ at the baseline survey may be shared. This could actually reveal the benefits to the children with moderate and mild levels of anemia.

This intervention study does not document the impact of fortification of biscuits with iron, as more than $200 \%$ of RDA of iron was administered to the children in 7-9 y of age.

\section{Compliance with Ethical Standards}

Conflict of Interest None.

Source of Funding None.

\section{References}

1. Bal D, Nagesh K, Surendra HS, Chiradoni D, Gomathy G. Effect of supplementation with iron fortified biscuits on the hemoglobin status of children in rural areas of Shimoga, Karnataka. Indian J Pediatr. 2015;82:253-9.

2. WHO. Haemoglobin concentrations for the diagnosis of anaemia and assessment of severity. Vitamin and Mineral Information System. Geneva: World Health Organization; 2011. Available at: http:// www.who.int/vmnis/indicators/haemoglobin/en/. Accessed 27 April 2015.

3. Indian Council of Medical Research: Nutrient requirements and recommended dietary allowances for Indians. A report of the expert group of the Indian Council of Medical Research, National Institute of Nutrition, Hyderabad, 2010. 